\section{Application Method Affects Water Application Efficiency of Spray Stake- irrigated Containers}

\author{
William F. Lamack'and Alex X. Niemiera ${ }^{2}$ \\ Department of Horticulture, Virginia Polytechnic Institute and State University, \\ Blacksburg, VA 24061-0327
}

Additional index words. intermittent irrigation, irrigation scheduling, time-averaged application rate, pine bark, soilless media, Tagetes erects

Abstract. Studies were conducted to evaluate the effect of water application medium moisture deficit, water application rate, and intermittent application on water application efficiency $\{[($ amount applied - amount leached)/amount applied] $x 100\}$ of spray stakeirrigated, container-grown plants. Pine bark-filled containers were irrigated to replace moisture deficits of 600,1200 , or $1800 \mathrm{ml}$; deficits were returned in single, continuous applications of 148,220 , or $270 \mathrm{ml} \cdot \mathrm{min}^{-1}$. Efficiency was unaffected by application rate but decreased with increased medium moisture deficit. In the second experiment, container medium at a $600-\mathrm{ml}$ deficit was irrigated with 400 or $600 \mathrm{ml}(6570$ and $100 \%$ water replacement, respectively); deficits were returned in a single, continuous application or in intermittent $100-\mathrm{ml}$ applications with 30-min intervals between irrigations. Application efficiency was greater with intermittent irrigation $(95 \%$ and $84 \%$ for 400 - and $600-\mathrm{ml}$ replacement, respectively) than with continuous irrigation (84\% and $67 \%$ for 400 - and 600-ml replacement, respectively). In the third experiment, pine bark was irrigated with $600 \mathrm{ml}$ water $(100 \%$ replacement) in $50-, 100-$, or $150-\mathrm{ml}$ aliquots with 20,40 , or $60 \mathrm{~min}$ between applications in a factorial design. Efficiency increased with decreasing application volume and increasing time between applications. Highest efficiency $(86 \%)$ was achieved with an irrigation regimen of $50-\mathrm{ml}$ applications with at least $40 \mathrm{~min}$ between applications, compared to $62 \%$ for the control treatment (a single, continuous application of $600 \mathrm{ml}$ ). Our results suggest that growers using spray stakes would waste less water by applying water intermittently rather than continuously.

Drip (trickle) irrigation can significantly increase water application efficiency compared to overhead irrigation (Bonaminio and Bir, 1983; Weatherspoon, 1977; Weatherspoon and Harrell, 1980), because emitters are in the container and deliver water directly to the medium (Furuta, 1973). Weatherspoon and Harrell (1980) found that application efficiency of drip systems ranged from $44 \%$ to $72 \%$. With drip irrigation, water is dripped onto a small

Received for publication 24 Aug. 1992. Accepted for publication 4 Dec. 1992. We acknowledge the Virginia Nurserymen's Association for their support of this research. We gratefully acknowledge the assistance of Carol Leda. Use of trade names does not imply endorsement of the products named nor criticism of similar ones not named. The cost of publishing this paper was defrayed in part by the payment of page charges. Under postal regulations, this paper therefore must be hereby marked advertisement solely to indicate this fact.

'Graduate Student.

${ }^{2}$ Assistant Professor. area of the medium's surface and results in little lateral water movement, especially in porous, soilless potting mixes (Furuta, 1973). Spray stake irrigation, a variant of drip irrigation, is similar to microsprinkler irrigation in that water is sprayed across the medium's surface and results in more lateral water distribution and, thus, a more thorough wetting of the medium compared to drip (Hoadley and Ingram, 1982).

In spray stake irrigation, water is applied directly into containers, whereas with sprinkler irrigation, water also falls between containers. However, spray stake irrigation can cause excessive leaching, especially with porous, soilless potting mixes (personal observation), due to the high application rates of emitters. Comparing commercially used irrigation emitters and sprinkler nozzles shows that spray stake irrigation application rates are 15 times higher than those of overhead sprinklers. A low drip application rate increases application efficiency by increasing lateral water movement and decreasing channeling (Hoadley and Ingram, 1982). Pre-irrigation moisture content also affects application efficiency. Rewetting pine bark, a widely used medium, that has dried excessively between irrigations can be difficult due to the hydrophobic nature of the dry particles. Even subsequent irrigations that result in excessive leaching do not rewet bark evenly due to water channeling through the medium (Powell, 1987).

Spray stake application efficiency may be increased by intermittent irrigation-applying daily water allotment in a series of cycles; each cycle comprises an irrigation and a resting interval (Karmeli and Peri, 1974; Mostaghimi and Mitchell, 1983). Intermittent irrigation increases application efficiency by decreasing application rate (volume applied divided by unit time). This method reduced vertical water movement below the root zone in mineral soils compared to a single totalvolume application (Jackson and Kay, 1987; Levin and van Rooyen, 1977; Levin et al., 1979; Mostaghimi and Mitchell, 1983). Intermittent application rate is time-averaged (Zur, 1976), which comprises the nominal application rate of the emitter, application duration, and interval between applications (Zur, 1976). Each water application is delivered at a high rate, but, when the interval between applications is taken into account, the time-averaged application rate is low (Karmeli and Peri, 1974). Several reports on the influence of application volume on mineral soils (Levin and van Rooyen, 1977; Levin et al., 1979) showed that emitter irrigation efficiency can be improved by decreasing the volume delivered at each application.

Intermittent irrigation of container-grown plants has increased application efficiencies with overhead sprinklers (personal observation) and drip irrigation (Ball, 1989; Stefanczyk, 1984; Weatherspoon, 1977; Weatherspoon and Harrell, 1980). The purpose of this study was to investigate application efficiency as affected by 1) pre-irrigation medium moisture deficits, 2) continuous vs. intermittent water application, and 3) intermittent application volume and frequency.

Tagetes erects L. 'Apollo' seedlings were transplanted to 11-liter plastic containers filled with pine (Pinus taeda L.) bark medium amended with $3 \mathrm{~kg}$ dolomitic lime/ $\mathrm{m}^{3}$. 'Apollo' was used for its rapid growth and large size . Bark had a bulk density of $0.19 \mathrm{~g} \cdot \mathrm{cm}^{-3}$, air space of $20.3 \%$ (volume water drained/volume of sample), total porosity of $84.8 \%$ (container capacity + air space), and container capacity of $63.5 \%$ [(wet weight-dry weight)/ 
volume] (determined using soil sampling cylinders with a $7.6-\mathrm{cm}$ diameter and $7.6-\mathrm{cm}$ height). Bark particle size distribution was $13.7 \%>5.66 \mathrm{~mm}, 26.9 \%>2.36 \mathrm{~mm}, 18.2 \%$ $>1.19 \mathrm{~mm}, 20.3 \%>0.5 \mathrm{~mm}$, and $20.7 \%<0.5$ $\mathrm{mm}$. Plants were irrigated by hand and fertilized three times weekly with $\approx 1000 \mathrm{ml}$ of a 150-mg N/liter solution (Peters 20N-5P-30K; Orate-Sierra, Milpitas, Calif.) until the start of the experiment ( $\approx 60$-day-old plants). At the start of all experiments, the bark was irrigated thoroughly with a watering wand to $94 \%$ container capacity. In all experiments, plants were grown in containers to extract water from the medium to specific moisture deficits. Following irrigation, evapotranspiration losses were determined by weighing, and, when bark reached the respective moisture deficits, shoots were severed at the medium surface to eliminate transpiration during treatment and container drainage. Since containers reached targeted moisture deficits at different times, appropriately moisture-depleted containers were sealed in plastic bags until treatments commenced to prevent further moisture loss. Lowand high-flow Roberts Spot Spitters (part no. 030-001003 and 030-001002, respectively; Roberts Irrigation Products, San Marcos, Calif.) spray stakes recommended for 11-liter containers were used for water application. One spray stake was located at the perimeter of each container and pointed toward its center. Experiments were conducted in a completely randomized design with 10 replications per treatment.

Influence of application rate on application efficiency at three moisture deficits. Bark was dried to three moisture deficits: 600,1200 , and $1800 \mathrm{ml} /$ container, which corresponded to $85 \%, 76 \%$, and $67 \%$ of container capacity, respectively. When all containers reached targeted moisture deficits, they were spray stakeirrigated (pressure $=55.2 \mathrm{kpa}$ ) with $100 \%$ of the water needed to apply the desired moisture deficits. Containers were irrigated at 148 (lowflow stake), 220 , or $270 \mathrm{ml} \cdot \mathrm{min}^{-1}$ (high-flow stake) in factorial combination with each of the three moisture deficits noted. Leachate from containers drained into collecting trays for $1 \mathrm{~h}$ after irrigation and was measured. Leachate volumes were used to calculate application efficiency using the following formula \{[(amount applied - amount leached)/ amount applied] $\times x$ 100]. Efficiency, expressed as a percentage, was tested for normal distribution, and arcsin transformation was unnecessary. Significance of interaction was tested by analysis of variance (ANOVA). This experiment was conducted twice and results of this duplication were similar;, subsequent experiments were conducted once.

Intermittent vs. continuous irrigation. Bark was allowed to dry to a moisture deficit of 600 $\mathrm{ml}$, followed by shoot severance. Containers were irrigated $\left(148 \mathrm{ml} \cdot \mathrm{min}^{-1}\right)$ with 600 or 400 $\mathrm{ml}$, which coincided with $100 \%$ and $\approx 65 \%$ of the moisture deficit, respectively, in factorial combination with two irrigation methods: continuous (total volume applied in one application) or intermittent (six 100-ml applications with 30 min between applications). Leachate
Table 1. Application efficiency of continuous and intermittent irrigation at two deficit replacement values.

\begin{tabular}{|c|c|c|}
\hline \multirow[b]{2}{*}{ Method } & \multicolumn{2}{|c|}{$\begin{array}{c}\text { Deficit } \\
\text { replacement }(\%)\end{array}$} \\
\hline & 65 & 100 \\
\hline \multicolumn{3}{|c|}{ Application efficiency (\%) } \\
\hline Continuous & $84.6^{z}$ & 67.4 \\
\hline Intermittent & 94.9 & 83.7 \\
\hline
\end{tabular}

${ }^{{ }^{\mathrm{SE}} \text { for all data }}=4.7, \mathrm{n}=40, P \leq 0.05$. 83.7

Table 2. Application efficiency after 300 and $600 \mathrm{ml}$ were applied with 50-, 100-, or 150-ml applications (pooled over time intervals between applications).

\begin{tabular}{lcr}
\hline \hline Application & \multicolumn{2}{c}{ Vol applied } \\
\cline { 2 - 3 } vol $(\mathrm{ml})$ & 300 & 600 \\
\hline \multirow{3}{*}{50} & Application & effciency $(\%)$ \\
100 & $98.9^{2}$ & 83.3 \\
150 & 96.8 & 72.1 \\
& 95.8 & 69.3 \\
\hline SE for all data=4.7, $\mathrm{n}=180, P \leq 0.05$.
\end{tabular}

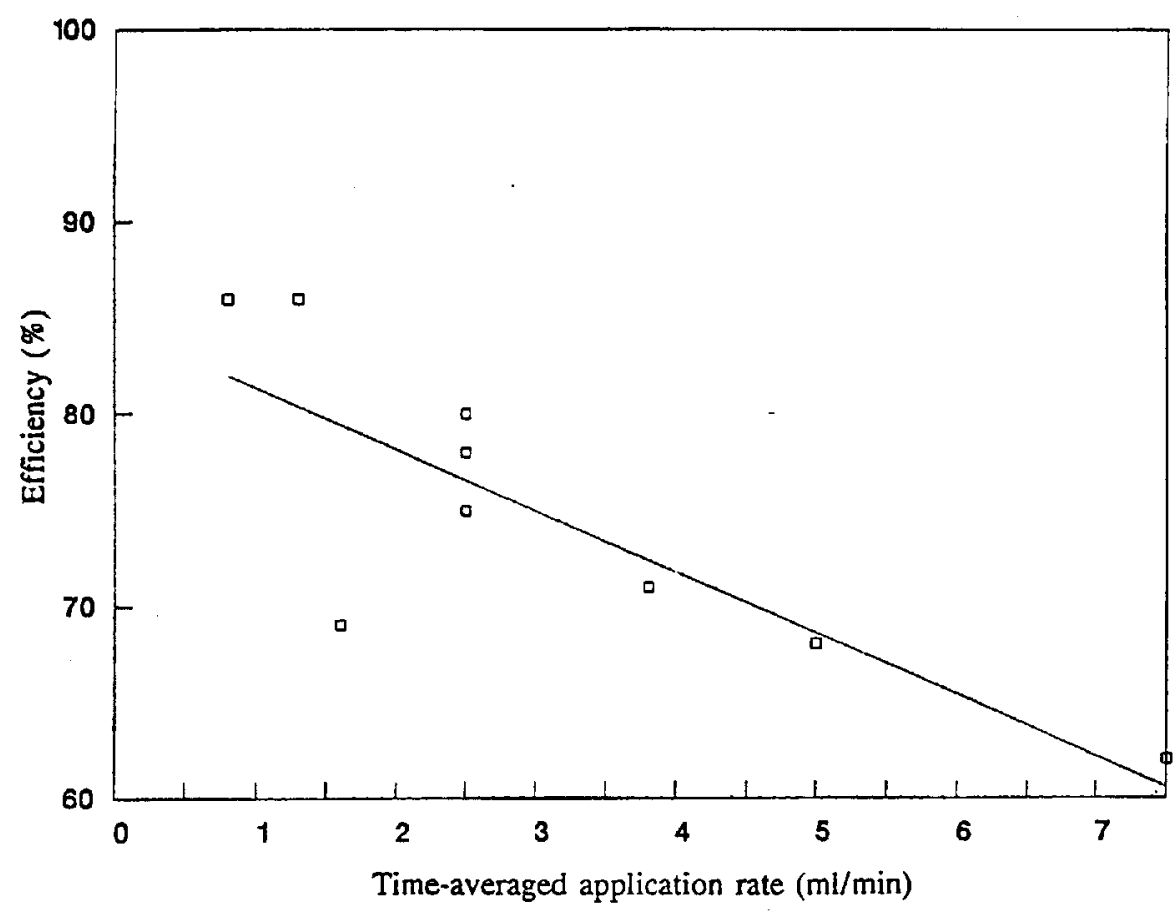

Fig. 1. Relationship between time-averaged application rate and application efficiency. Data points represent treatment means $\left(\mathrm{n}=180, r^{2}=-0.82, P=0.01\right)$.

volume was measured at the end of each interval just before starting the next application. Following the last application, containers drained for $1 \mathrm{~h}$. and leachate was measured.

Influence of volume and application frequency on intermittent application efficiency. As in the previous experiment, water was withheld from plants until a deficit of $600 \mathrm{ml}$ was attained. Then $600 \mathrm{ml}$ was applied (148 $\left.\mathrm{ml} \cdot \mathrm{min}^{-1}\right)$ in a $3 \times 3$ factorial combination of three application volumes $(50,100$, or $150 \mathrm{ml})$ with three intervals between applications (20, 40 , or 60 rein); in each combination, $100 \%$ $(600 \mathrm{ml})$ was replaced by controlling application duration. A control treatment was included in which $600 \mathrm{ml}$ was applied in a single continuous application. Collected leachate was measured at the end of each interval.

Influence of application rate on application eficiency at three moisture deficits. Interaction between application rate and moisture content was absent, and application rate did not affect application efficiency (data not shown). Efficiency was $65 \%, 51 \%$, and $53 \%$ (different according to ANOVA, $P=0.05$ ) for medium moisture deficits of 600,1200 , and $1800 \mathrm{ml}$, respectively. Bark at low moisture content has hydrophobic properties that result in water channeling during irrigation. In a preliminary experiment, sectioning container medium into top, middle, and bottom thirds revealed more channeling in a dry medium compared to a medium with a lower deficit (data not shown). The highest efficiency (65\%) resulted when the moisture deficit was $600 \mathrm{ml}$ and was similar to other work (Weatherspoon, 1977; Weatherspoon and Harrell, 1980) in which application efficiencies of various drip or trickle systems ranged from $44 \%$ to $72 \%$. However, directly comparing efficiencies between studies is difficult due to media differences and unreported medium moisture contents or deficits.

Intermittent vs. continuous irrigation methods. Efficiency was higher when water was applied intermittently rather than continuously; degree of efficiency depended on the amount of deficit replacement (Table 1). Efficiency was high for intermittent irrigation and continuous application at $65 \%$ replacement. Efficiency for the continuous treatment at $100 \%$ return was $17 \%$ lower than with $65 \%$ replacement. This low efficiency is similar to those reported by Weatherspoon (1977) and Weatherspoon and Harrell (1980). Because most growers apply water in excess of deficit 
(personal observation), the advantage of spray stake over sprinkler irrigation is greatly reduced.

For intermittent irrigation, the $11 \%$ lower efficiency at $100 \%$ replacement than at $65 \%$ is explained by the 100-ml application efficienties. The efficiency following the first three $100-\mathrm{ml}$ applications was $100 \%$. Overall efficiencies following the fourth (9690), fifth (89\%), and sixth (84\%) 100-ml applications decreased linearly $\left(P=0.0001, r^{2}=0.87\right)$. Thus, after $300 \mathrm{ml}$ is applied, a water-holding thresholds reached, beyond which bark can no longer absorb water as fast as it is applied.

Influence of volume and frequency on intermittent application efficiency. Length of time between applications and application volume acted independently. Application efficiencies (pooled overtime intervals) decreased for application volumes of 50,100, and $150 \mathrm{ml}$ when $600 \mathrm{ml}$ was applied (Table 2). Efficiencies (pooled over application volumes) were $69 \%, 79 \%$, and $77 \%$ for intervals of $20-, 40-$, and 60-min applications, respectively (different according to ANOVA, $P \leq 0.05)$.

Efficiency was highest (86\%) with a regimen of 50-ml applications and at least $40 \mathrm{~min}$ between applications. Efficiency of the control treatment (total deficit returned in a single, continuous application) was $62 \%$. All irrigation regimens, except the $150-\mathrm{ml}$ application with a 20 -min interval, were more efficient than the control treatment. The irrigation regimens that produced the highest efficiency (86\%)-50-ml applications with 40-min intervals and 50-ml applications with 60-min intervals-also had the lowest time-averaged application rates; i.e., 1.3 and $0.8 \mathrm{ml} \cdot \mathrm{min}^{-1}$, respectively. The fact that three of the regimens-50-ml applications with 20-min intervals, $100-\mathrm{ml}$ applications with 40-min intervals, and 150-ml applications with 60-min intervals-had the same time-averaged application rate $\left(2.5 \mathrm{ml} \cdot \mathrm{min}^{-1}\right)$ and produced efficiencies that were similar at $P=0.05$ indicates that the time-averaged application rate has merit in formulating irrigation regimens for soilless medium in containers. This contention is supported by the high inverse correlation of the time-averaged application rate and efficiency relationship (Fig. 1).

Regardless of application volume, efficiency following the fist 300-ml application ( $\approx 100 \%$ ) was greater than that following the second (Table 2). After $600 \mathrm{ml}$, water drained from the medium and differences between regimens were evident. As in the previous experiment, after $300 \mathrm{ml}$ was applied, a thresh- old was reached beyond which the bark's water absorption capacity decreased. These data show that the first $300 \mathrm{ml}$ could be delivered in two 150-ml applications with minimal leaching. Research is needed to determine how to increase the efficiency of the second $300 \mathrm{ml}$ of the $600-\mathrm{ml}$ deficit. In our study, we attempted to return the full moisture deficit, but Kiehl et al. (1992) and Lieth and Burger (1989) found that high-quality, containergrown chrysanthemums [Dendrathema $\times$ grandiflorum (Ramat.) Kitamura] could be grown at a medium moisture tension of 1 to 2 kpa. Since water deficits (tensions) that do not appreciably decrease plant quality are most likely related to species-specific tolerances, returning less than the total deficit may be adequate to maintain plant quality with a high application efficiency. Research is also needed to determine how to adjust fertilization practices when irrigating without leaching.

Because ammonium and nitrate ions are readily leached from pine bark (Foster et al., 1983; Thomas and Perry, 1980), the low efficiency of continuous spray stake irrigation would result in significant amounts of $\mathrm{N}$ leached from bark. Container nurseries can lose as much as $3226 \mathrm{~m}^{3}$ water/ha and $169 \mathrm{~kg}$ nitrate-N/ha through leaching and runoff when using continuous drip irrigation (Rathier and Frink, 1989). Using intermittent irrigation with drip irrigation could reduce water loss from containers by $42 \%$, which is equivalent to $1355 \mathrm{~m}^{3}$ water/ha, and also reduce annual $\mathrm{N}$ loss significantly. Using relatively inexpensive microprocessor-controlled irrigation controllers makes intermittent irrigation an easy and economical way to increase application efficiency without updating irrigation systems significantly or installing large-scale runoff capturing or recycling facilities. Most nursery operators apply nutrients at high rates and irrigate excessively to prevent soluble salt buildup. Because intermittent irrigation reduces leaching, we believe that fertilizer applications cart be reduced without reducing plant quality. This statement is supported by the work of Biernbaum et al. (1989) and Ku and Hershey (1991).

\section{Literature Cited}

Ball, V. 1989. El Modeno's solutions to runoff regulations. Grower Talks 53(5):2425.

Biernbaum, J., M. Yelanich, W. Carlson, and R. Heins. 1989. Irrigation and fertilization go hand in hand to reduce runoff. Grower Talks 53(3):26 30.

Bonaminio, V.P. and R.E. Bir. 1983. Growth of containerized plants under drip or overhead irrigation. Proc. Southern Nurserymen's Assn. Res. Conf. 28:20-23.

Foster, W. J., R.D. Wright, M.M. Alley, and T.H. Yeager. 1983. Ammonium adsorption on a pinebark growing medium. J. Amer. Soc. Hort. Sci. 108:548-551.

Furuta, T. 1973. New irrigation system speeds water to entire nursery. Amer. Nurseryman 21:13, 93 100.

Hoadley, B. and D.L. Ingram. 1982. Drip irrigation for the woody ornamental nursery. Southern Florist Nurseryman 95(14):20-23.

Jackson, R.C. and M.G. Kay. 1987. Use of pulse irrigation for reducing clogging problems in trickle emitters. J. Agr. Eng. Res. 37:223-227.

Karmeli, D. and G. Peri. 1974. Basic principles of pulse irrigation. J. Irr. Drainage Div. 100(IR3):309-319.

Kiehl, P.A., J.H. Lieth, and D.W. Burger. 1992. Growth response of chrysanthemum to various container medium moisture tensions. J. Amer. Soc. Hort. Sci. 117:224-229.

Ku, C.S.M. and D.R. Hershey. 1991. Leachate electrical conductivity and growth of potted poinsettia with leaching fractions of 0 to 0.4 . J. Amer. Soc. Hort. Sci. 116:802-806.

Levin, I. and F.C. van Rooyen. 1977. Soil water flow and distribution in horizontal and vertical directions as influenced by intermittent water application. Soil Sci. 124:355-365.

Levin, I., P.C. van Rooyen, and F.C. van Rooyen. 1979. The effect of discharge rate and intermittent water application by point source irrigation on the soil moisture distribution pattern. Soil Sci. Soc. Amer. J. 43:8-16.

Lieth, J.H. and D.W. Burger. 1989. Growth of chrysanthemum using an irrigation system controlled by soil moisture tension. J. Amer. Soc. Hort. Sci. 114:387-392.

Mostaghimi, S. and J.K. Mitchell. 1983. pulsed trickling effects on soil moisture distribution. Water Resources Bul. 19(4):605-612.

Powell, D. 1987. Water absorbents vs. wetting agents-What's the difference? Amer. Nurseryman 165(12):59-61.

Rathier, T.M. and C.R. Frink. 1989. Nitrate in runoff water from container grown juniper and Alberta spruce under different irrigation and $\mathrm{N}$ fertilization regimes. J. Environ. Hort. 7:32-35.

Stefanczyk, K. 1984. Trickle, drip, or mist? Florist's Rev. 174:21-23.

Thomas, S. and F.B. Perry, Jr. 1980. Ammonium nitrogen accumulation and leaching from an all pine bark medium. HortScience 15:824-825.

Weatherspoon, D.M. 1977. An initial evacuation of drip irrigation on woody ornamentals in containers. Proc. Fla. State Hort. Soc. 90:306-308.

Weatherspoon, D.M. andC.C. Harrell. 1980. Evacuation of drip irrigation for container production of woody landscape plants. HortScience 15:488489.

Zur, B. 1976. The pulsed irrigation principle for controlled soil wetting. Soil Sci. 122:282-291. 